Chirurgia (2019) 114: 824-825

No. 6, November - December Copyright $@$ Celsius

http://dx.doi.org/10.21614/chirurgia.114.6.824

\section{Surgery of the Esophagus}

\section{Silviu Constantinoiu, Coordinator}

Editura Academiei Române, Bucharest 2019

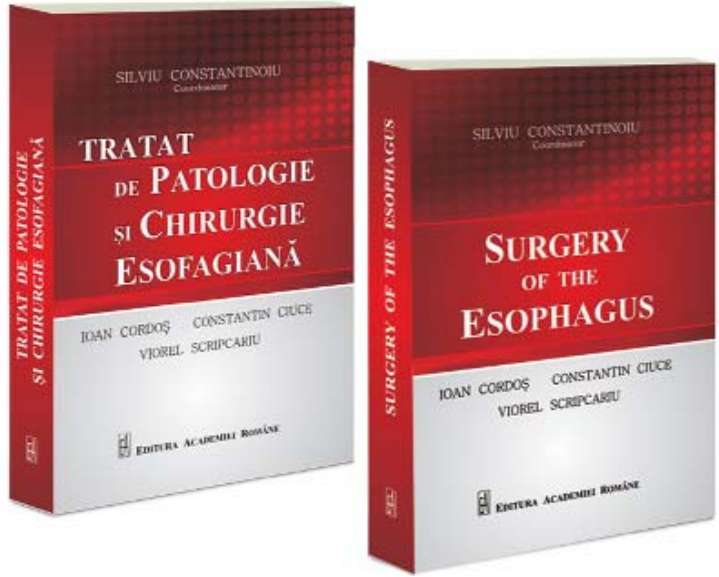

expression above fits perfectly to the coordinator, who is also the first author. I can easily state that only a lionhearted person like he is could have accomplished what he managed to do in the Romanian surgery. Hence, I can wittingly affirm that this bilingual Romanian English Treatise is a unique monument.

\section{Why a monument?}

Because the Treatise comprises all the pathology and surgery of the oesophagus, starting with the history of this surgery, where the Romanians have world premieres, followed by the anatomy, the oesophageal exploration and its entire pathology: reflux disease, movement disorders, trauma, parasitic and inflammatory diseases, benign and malignant tumours, and the vast majority of classical, minimally invasive and most recently - endoscopic oesophageal surgical procedures.

The architect of this surgical literature monument, professor Silviu Constantinoiu, brought around him other operating surgeons. Why do I emphasize the operating surgeons? Because unfortunately, we have a particular category of surgeons, who do not perform surgeries even if they have a surgeon diploma. 
And unfortunately, these nonoperating surgeons stonewall the operating surgeons, even more, they might be their bosses.

The operating surgeons of general surgery are few, and sadly, they are fewer in thoracic surgery, especially those who perform operations of the oesophagus. The surgeons who came alongside professor Constantinoiu are Prof. Ioan Cordoş, Prof. Constantin Ciuce from Cluj, Prof. Viorel Scripcaru from Iaşi and their collaborators. Naturally, the largest team is the one working under the supervision of Prof. Constantinoiu, at the "Saint Mary" Hospital in Bucharest. All these authors have performed oesophageal surgeries or were part of the surgical team. Due to the coordinator's endeavour, there are operating surgeons from the Americas who came along alongside the Romanian authors, together with Marcel Tătaru, a Romanian gastroenterologist, a pioneer in the oesophageal endoscopic procedures and the physicians Radu Stoica and Genoveva Cadar, well-known anaesthesiologists in the thoracic anaesthesiology.

\section{Why is this treatise one-of-a-kind?}

It is straightforward. Because no other Romanian surgeon, with international and national notoriety, has put in writing such a complex surgical literature endeavour. Definitely, through my affirmation, I don't underestimate the activity of other surgeons in the domain of the oesophagus.

\section{Why was it necessary to have an English translation of the treatise?}

The first reason for which this treatise was published at the Publishing House of the Romanian Academy and printed at the "Curtea Veche" typography was that the entire world to see that Romania had pioneers in the oesophageal surgery and still has successors who practice surgery at a high level, as well as high-class typographies.
For others to know that the reversed gastric tube oesophagoplasty was the idea of the Romanian Amza Jianu, who lived and operated in Bucharest, and not in another capital city from the West of Romania, as some books of oesophageal surgery from America and Western Europe state.

For others to find out and remember that all the foreign treatises on the subject of the oesophagus written in English, French, German, Russian, Japanese, etc., quote Dan Gavriliu, a great operating surgeon from the second half of the XX century, born in Romania.

For the Western world to see that other Romanian surgeons practised oesophageal surgery, among which Zeno Popovici, respected and appreciated abroad, more than in his own country.

For everyone to see that oesophageal surgery is not dead in Romania, on the contrary, it has developed and diversified.

As a result of the above, for the foreigners to increase their respect towards the Romanian surgeons, who were capable of writing this treatise, written from their own surgical experience and on the analysis and integration of the expertise of surgeons from Europe, Asia and the two Americas. I have to say that surgery, and particularly oesophageal surgery, does not know anything about ideology, and the disease does not take account of ideological affiliation nor of ethnical criteria.

I am convinced that the "Surgery of the Esophagus" treatise - the English translation of the Treatise of Oesophageal Pathology and Surgery under the coordination of professor Silviu Constantinoiu, published at the Publishing House of the Romanian Academy and printed at the "Curtea Veche" typography, will lead to the increase of prestige of the Romanian Surgical School at an international level and also in our country, where we live and where we were born.

Profesor Doctor Teodor Horvat 